\title{
Retrieving leaf area index (LAI) of Phragmites australis in Panjin wetland of China
}

\author{
Yanfeng Li \\ Northeast Institute of Geography and Agroecology, \\ Chinese Academy of Sciences \\ Changchun, China \\ University of Chinese Academy of Sciences \\ Beijing, China
}

\begin{abstract}
Based on Landsat7 ETM+ imagery and groundmeasured Leaf area index (LAI) data, a optimal estimation model was developed in order to accomplish the retrieval of Phragmites australis LAI in Panjin Wetland of China. To obtain more knowledge about the actual status of Phragmites australis, the spatial pattern of LAI was also analyzed. Results showed that: in 2012, Phragmites australis area in Panjin is 58,393ha. Multivariate linear model regarding the ratio vegetation index (RVI), two mid-infrared spectral bands $\left.\left(\text { Band }_{5} \text { and } B^{-}\right)_{7}\right)$ as independent variables is the optimal estimation model of Phragmites australis LAI $\left(p<0.01, R^{2}=0.727\right)$. The spacial difference of Phragmites australis LAI is very evident, and basically decreases from northeast to southwest of Panjin wetland.
\end{abstract}

Index Terms-Phragmites australis, Leaf Area Index (LAI), Panjin wetland, Landsat7 ETM+ imagery, multi-season satellite imagery.

\section{INTRODUCTION}

Leaf Area Index (LAI), defined as half of the total leaf area per unit ground surface area ${ }^{[1]}$, is a key component of biogeochemical cycles in ecosystems and an important biophysical parameter in the studies about atmosphereecosystem interaction and global change. LAI plays an significant role in vegetation monitoring and protection ${ }^{[2,3]}$. At present, LAI assessment in large-scale area are mainly achieved through regressive models and physically-based models. Compared with the physically-based models, regressive models based on remote sensing data are simple and require fewer necessary parameters. Therefore, they have been widely used in various types of vegetation monitoring, such as crop, grassland and forest ${ }^{[4-5]}$.

In recent years, researchers have been paid more attentions to the studies on wetland LAI. On the basis of precise classification of wetland types, establishing a precise LAI estimation model became the focus of studying wetland vegetation $\mathrm{LAI}^{[6-7]}$.,However, there are still some problems existing in current studies. The generally-recognized vegetation indices (VIs) are the most widely used to establish LAI estimate models in most of studies. However, the method for establishment of LAI estimate model, i.e., combining reflectance data of spectral bands with various VIs, has been successfully applied in studies on other types of vegetation ${ }^{[8-9]}$. Moreover, using hyperspectral technology can improve accuracy for LAI estimation. But, because of limitations in the

\author{
Dehua Mao*, Zongming Wang, Chunying Ren \\ Northeast Institute of Geography and Agroecology \\ Chinese Academy of Sciences \\ Changchun, China
}

model application, it is difficult to achieve the dynamic monitoring of vegetation at a large scale during a short period. Hence, it is necessary to give a further study on how to make full use of the multi-spectral information of remote sensing imagery to develop the LAI estimation of wetland vegetation.

Panjin, a considerable production base of Phragmites australis, has rich wetland resources. Owing to climate change and development of economy, the living environment of vegetation in Panjin wetland is trending to deteriorate. Therefore, a quantitative study for the vegetation growing status in Panjin wetland is necessary. In present study, based on Landsat7 ETM+ imagery, we use univariate and multivariate statistic methods to establish the Phragmites australis LAI estimate model, then map the spatial pattern of LAI, which aims to provide scientific guidance for wetland management.

\section{STUDY AREA AND METHODS}

\subsection{Study area}

Panjin, located between $121^{\circ} 25^{\prime} \mathrm{E}-122^{\circ} 31^{\prime} \mathrm{E}$ and $40^{\circ} 39^{\prime} \mathrm{N}-$ $41^{\circ} 27^{\prime} \mathrm{N}$, lies in the southern part of Liaohe River Plain and middle of Liaohe River Delta (Fig.1). It has relative warm and wet climate, of which the annual average temperature is $8.4^{\circ} \mathrm{C}$ and the annual precipitation is $611.6 \mathrm{~mm}$. The types of soil in Panjin can be divided into saline soil, meadow soil, tidal flat soil, swamp soil, and so on. Panjin has rich wetland resources. Main vegetation types in Panjin wetland are natural wetland vegetation communities such as Phragmites australis, suaeda, and artificial wetland such as rice field. Panjin wetland, which is abundant in bird resources, is the second largest Phragmites australis wetland in Asia. Both in terms of the area and multifunction of this wetland, it is representative in Phragmites australis wetlands, whether in China or in the world. 


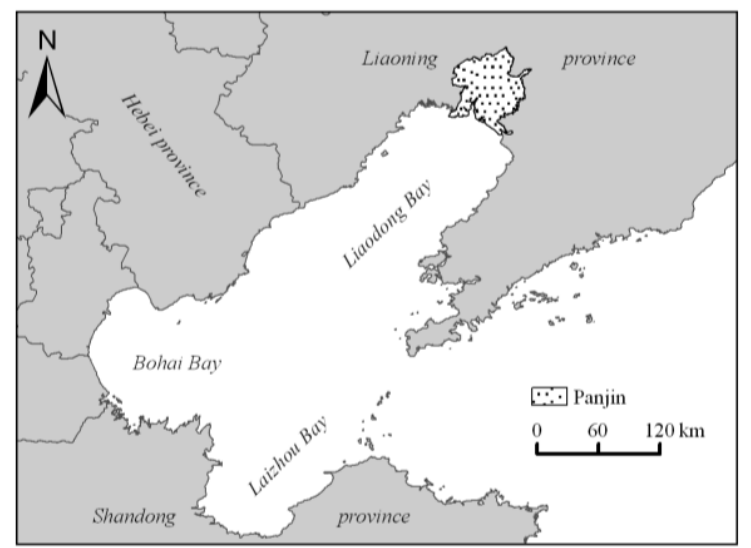

Fig.1 Location of the study area

\subsection{Methods}

\subsubsection{Data collection and processing}

The study area can be covered with two single Landsat 7 ETM+ scenes (path120/ row 31, path120/ row 32). A seasonal time series of images were acquired on 28 May, 16 August 19 October in 2012. These date had been selected based on vegetation phenology and seasonal water management of the wetland. Cloud-free images in 16 August 2012 were used to LAI retrieval. The software of ENVI 4.8 was applied to remove the strip band and conduct radiometric calibration and atmospheric correction using $6 \mathrm{~S}$ radiative transfer model. Remote sensing images were geo-rectified to 1: 100,000 topographic maps using ground control points (GCPs). Each image had at least 20 evenly distributed GCPs.

The distribution of Phragmites australis was extracted by object-oriented multi-season classification method ${ }^{[10]}$ on eCognition software platform. In addition to ETM+ images in May, August and October, filed survey records were regarded as the auxiliary data. Meanwhile, unsupervised classification was carried out using the interactive self-organizing data analysis (ISODATA) algorithm to identify spectral clusters in the images in order to extract the residential land and water body. Finally, the classification accuracy was assessed using the 195 verification points acquired from field investigation in 2012 and Google Earth online software, and the overall classification accuracy was $89.5 \%$.

LAI measurements were performed in early August, 2012. A ground-based optical instrument, LAI-2000, was used to measure canopy LAI under clear diffuse skies at low solar elevationclear and usually at the same local time each day. We conducted field surveys at 65 plots $(30 \mathrm{~m} \times 30 \mathrm{~m})$, and a handheld GPS was used to locate their centers' positions in the field. Three subplots $(1 \mathrm{~m} \times 1 \mathrm{~m})$ randomly selected within each plot were identified. The average value of the three subplots' measured LAI values was considered to represent LAI value of each plot. As a result, measured LAI values of 65 plots were produced, in which 61 plots' measured LAI values were remained after removing the outliers. Then measured LAI values of 46 plots were randomly selected for modeling and the other 15 plots were used for validation.

2.2.2 Correlation and regression analyses of LAI with spectral variables
Correlation and regression analyses were applied in establishing the estimate model for Phragmites australis LAI. In this paper, 10 spectral variables were selected, including six single ETM + band reflectances $\left(\right.$ Band $_{1-5}$ and Band $\left._{7}\right)$, four $\mathrm{VIs}^{[11]}$ (table 1). Arcgis 9.3 software was used to extract the mean value of each variables from the imagery at each sample site on a pixel-by-pixel basis. Correlation analysis between ground-measured LAI values and 10 variables were performed using the SPSS software, then the variables which were significantly related to the LAI were selected. After that, univariate regression linear or non-linear analysis was proceed using the selected single variables as the independent variables and in situ LAI as the dependent variable. In multivariate regression modeling, because there is much redundant information among the ETM+ single band reflectances and four VIs, the stepwise regression method ${ }^{[8]}$ was used in order to select independent variables and eliminate the multicollinearity phenomenon.

TABLE I . Vegetation Indices

\begin{tabular}{cc}
\hline $\begin{array}{c}\text { Vegetation } \\
\text { Index }\end{array}$ & Formula \\
\hline$N D V I$ & $\frac{\rho_{\text {NIR }}-\rho_{R}}{\rho_{\text {NIR }}+\rho_{R}}$ \\
$E V I$ & $\frac{2.5\left(\rho_{N I R}-\rho_{R}\right)}{\rho_{N I R}+6.0 \rho_{R}-7.5 \rho_{R}+1}$ \\
$R V I$ & $\frac{\rho_{N I R}}{\rho_{R}}$ \\
$M S A V I$ & $0.5 \times\left[2 \rho_{N I R}+1-\sqrt{\left(2 \rho_{N I R}+1\right)^{2}-8\left(\rho_{N I R}-\rho_{R}\right)}\right]$ \\
\hline
\end{tabular}
respectively.

\subsubsection{Accuracy assessment criteria}

The retrieved LAI results would be compared to field measured LAI. Coefficient of determination $\left(\mathrm{R}^{2}\right)$, root mean squared error (RMSE) and accuracy ${ }^{[8]}$ were selected to assess the estimation accuracy of the models. The calculating formulas were as followed.

$$
\begin{aligned}
& R M S E=\sqrt{\frac{\sum_{i=1}^{n}\left(Y_{i}-Y_{i}^{\prime}\right)^{2}}{N}} \\
& \text { Accuracy }=(1-R M S E / \bar{Y} \times 100 \%)
\end{aligned}
$$

Where $Y_{i}(i=1,2, \ldots, \mathrm{n})$ are actual LAI measurements; $Y_{i}^{\prime}(i$ $=1,2, \ldots, \mathrm{n}$ ) are LAI values estimated by a model (univariate model or multivariate model); $N$ is the number of samples (either training or test samples).

\section{RESULTS}

\subsection{Developing and accuracy validation forPhragmites australis LAI estimate model}

Correlation analysis between ground-measured LAI values and each of 10 variables (six single ETM+ band reflectances and four VIs) was performed using 46 samples. Through correlation analysis, the correlation coefficients between variables and measured LAI are showed in fig.2. The correlation between 7 variables (RVI, NDVI, EVI, MSAVI, 
B4, B3 and B5) and LAI is significantly correlated at 0.01 confidence level.

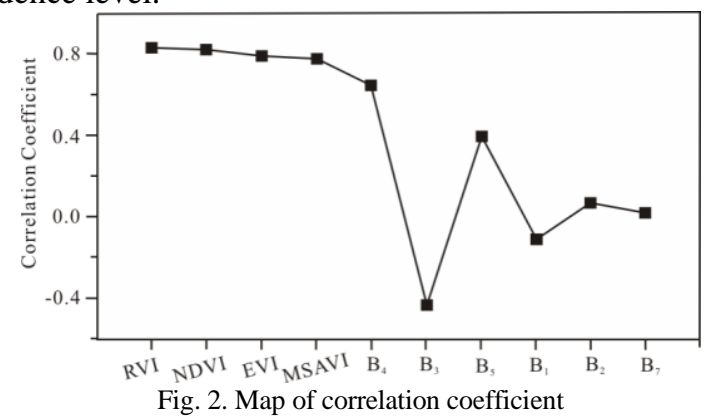

Considering the 7 spectral variables as independent variables and LAI as the dependent variable, the univariate regression optimal model was achieved. Regarding all 10 spectral variables as independent variables and LAI as the dependent variable, multivariate linear regression model was established. The optimal univariate and multivariate linear regression expressions of the spectral variables with LAI, in association with $\mathrm{R}^{2}$ and RMSE values, are presented in table 2 and table 3 . All models in the tables have been approved by significance testing at the 0.01 confidence level.

As we can see from table 2 and table 3 , the regression model, which takes RVI as independent variables, gets the optimal fitting result with the maximum $\mathrm{R}^{2}$ and the least RMSE in various univariate regression models. Compared with the univariate regression optimal model, which takes RVI as independent variables, the multivariate linear regression model with $\mathrm{B}_{5}, \mathrm{~B}_{7}$, and RVI as independent variables has the larger $\mathrm{R}^{2}$ and the smaller RMSE. The tolerance of multivariate linear regression model is 0.2 . Hence there is no multicollinearity phenomenon existed in this model. Obviously, the multivariate linear regression model is the optimal estimate model of Phragmites australis LAI and its structural formula is as followed:

$L A I=16.09$ Band $_{5}-24.85$ Band $_{7}+0.51 R V I+0.98$

TABLE II . One element regression model of Phragmites australis LAI

\begin{tabular}{|c|l|c|c|c|}
\hline variables & Regression models & $\mathbf{R}^{\mathbf{2}}$ & RMSE & Sig \\
\hline$R V I$ & $y=2.39 \ln (x)+0.54$ & 0.687 & 0.459 & 0.000 \\
\hline NDVI & $y=6.23 x+0.10$ & 0.683 & 0.461 & 0.000 \\
\hline$M S A V I 2$ & $y=1.69 \ln (x)+5.98$ & 0.643 & 0.490 & 0.000 \\
\hline$E V I$ & $y=1.71 \ln (x)+5.73$ & 0.636 & 0.495 & 0.000 \\
\hline Band $_{4}$ & $y=12.47 x+0.97$ & 0.425 & 0.622 & 0.000 \\
\hline Band $_{3}$ & $y=-31.69 x+4.92$ & 0.186 & 0.740 & 0.002 \\
\hline Band $_{5}$ & $y=9.31 x+1.67$ & 0.162 & 0.750 & 0.004 \\
\hline
\end{tabular}

Notes: $x$ and $y$ in expressions represent LAI measurements and spectral variables, respectively.

TABLE III. Multiple linear regression model of Phragmites australis LAI

\begin{tabular}{|c|c|c|c|c|}
\hline Variables & Regression model & $\mathbf{R}^{2}$ & RMSE & Sig \\
\hline Band $_{5}$ & ${\text { LAI }=16.09 \text { Band }_{5}}$ & 0.711 & 0.437 & 0.001 \\
Band $_{7}$ & -24.85 Band $_{7}+$ & & & 0.017 \\
$R V I$ & $0.51 R V I+0.98$ & & & 0.025 \\
\hline
\end{tabular}

Comparing the measured values with the estimated values, the results are shown in figure 3 . There is a good linear correlation between measured LAI values and simulated LAI values. RMSE is 0.465 and model estimates accuracy is $85.8 \%$.

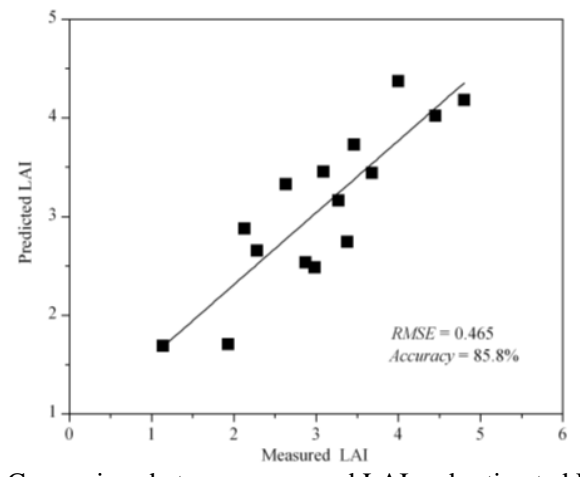

Fig. 3. Comparison between measured LAI and estimated LAI

\subsection{Mapping and spatial pattern analysis about Phragmites} australis LAI

According to the extracting method, the distribution information of three land use types (Phragmites australis, residential land and water body) was extracted. In view of the statistics, the area of Phragmites australis in Panjin in 2012 is 58,393 ha, accounting for $16.0 \%$ of the total area of Panjin .

Applying the established optimal estimate model (calculating formula (3)) for Phragmites australis LAI estimate, Phragmites australis LAI map is achieved. From Fig.4, it is known that Phragmites australis is predominantly distributed in the west of Panjin. The Phragmites australis LAI in Panjin wetland has an evident spatial difference, and basically decreases from northeast to southwest of the wetland. LAI is higher in Shuangtaizi River Basin, and lower in the southwest of Panjin wetland .

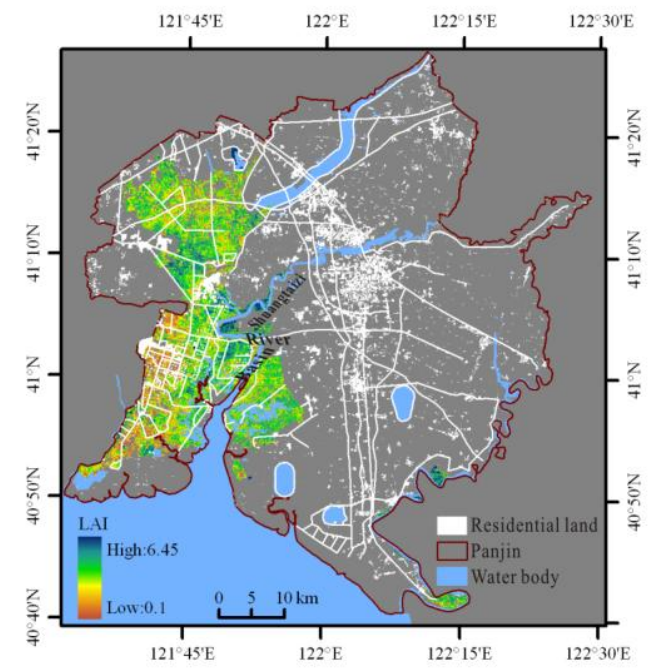

Fig.4. Mapping of Phragmites australis LAI in Panjin wetland

\section{DISCUSSION}

\subsection{The feasibility of the LAI estimate model}

With the advent of high spatial resolution and multi-spectral sensors, remote sensing technique have become particularly attractive for assessing vegetation biophysical parameters, such as LAI. The simple regression equation is intended for rapid prediction of LAI in a straightforward way ${ }^{[7-9,12]}$. Using VIs as independent variables to develop LAI estimate model and LAI retrieval, is one of the most commonly used methods. 
Several studies have showed that the best vegetation index used for estimating vegetable LAI was the RVI $\left(\mathrm{Band}_{4} / \mathrm{Band}_{3}\right)^{[7,12]}$. In this study, it is also found that among all developed univariate regression models, the model with four kinds of VIs has higher $\mathrm{R}^{2}$ and smaller RMSE. And, the model with RVI as independent variables achieved the optimal fitting result with a estimate accuracy of $81.7 \%$. This is reasonable because all four VIs were constructed with reflectances in red $\left(\right.$ Band $\left._{3}\right)$ and near-infrared $\left(\right.$ Band $\left._{4}\right)$, which efficiently combine the characteristics of wetland vegetation with high absorption in the Red region for photosynthesis and high reflectivity in the near-infrared band. However, the multivariate linear model in this paper performed better than all the univariate regression models, with higher estimate accuracy $(85.8 \%)$, which could be due to the applying of abundant spectral information of two mid-infrared spectral bands $\left(\right.$ Band $_{5}$ and Band $\left._{7}\right)$.

\subsection{Possible impacts of climate and human activities}

The differences in the natural environment and human activities could be the primary reasons that caused notable spatial differences of Phragmites australis LAI in Panjin wetland. Adequate water supply might contribute to the well growth of Phragmites australis in Shuangtaizi River Basin. On the contrary, a lack of water resource caused by a warm and dry climate in the southwest of Panjin wetland may be the main reason for wetland degradation. Meanwhile, with a large amount of oil fields and roads distributed in the southwest of the wetland (fig.4), serious water pollution caused by excessive oil exploration and the expansion of industry and agriculture is another important factor seriously restraining the growth of Phragmites australis ${ }^{[13]}$.

\section{CONCLUSIONS}

In this study, based on Landsat7 ETM+ imagery and ground-measured LAI data, a multivariate linear regression model with $\mathrm{B}_{5}, \mathrm{~B}_{7}$, and RVI as independent variables was finally selected to be the optimal estimate model for LAI. The multivariate linear regression model, making full use of the rich spectral band information of remote sensing imagery, improved performance by more than $4 \%$ of estimate accuracy than the univariate linear regression models. Based on the multivariate linear regression model, we successfully retrieved the Phragmites australis LAI in Panjin weland and found that it had an evident spatial difference, which might be caused by differences in natural environment and human activities in different regions. The conclusions should be beneficial for making governmental policies that encourage reasonable utilization and protection on wetland resources.

\section{ACKNOWLEDGMENT}

This study was supported by the National Basic Research Program of China (Nos. 2013CB430401 and 2012CB956103). We thank the participants involved in the construction of scientific database.

\section{REFERENCES}

[1] Chen J M, "Defining leaf-area index for non-flat leaves", Plant Cell Environ, Vol.15, 1992, pp.421-429.

[2] Wang Q, "Evaluation of seasonal variation of MODIS derived leaf area index at two European deciduous broadleaf forest sites”, Remote Sensing Environ,Vol.96, 2005, pp. 475-484.

[3] Zhang F M, "Evaluating spatial and temporal patterns of MODIS GPP over the conterminous U.S. against flux measurements and a process model", Remote Sensing of Environment, Vol.124, 2012, pp. 717-729.

[4] Anthony N R, "Green Leaf Area Index Estimation in Maize and Soybean: Combining Vegetation Indices to Achieve Maximal Sensitivity". Agronomy Journal, Vol.104,No.5, 2012, pp. 13361347.

[5] Gregory P, "Global synthesis of leaf area index observations: implications for ecological and remote sensing studies", Global Ecology \& Biogeography, Vol.12, 2003, pp. 191-205.

[6] Wang J F, "Mapping mangrove leaf area index at the species levelusing IKONOS and LAI-2000 sensors for theAgua Brava Lagoon, Mexican Pacific", Estuarine, Coastal and Shelf Science, Vol. 62, 2005, pp. 377-384.

[7] Roshanak D, "Estimation of vegetation LAI from hyperspectral reflectance data: Effects of soil type and plant architecture", International Journal of Applied Earth Observationand Geoinformation, Vol.10, 2008, pp. 358-373.

[8] $\mathrm{Pu} \mathrm{R} \mathrm{L}$, "Mapping leaf area index over a mixed natural forest area in the floodingseason using ground-based measurements and Landsat TM imagery". International Journal of Remote Sensing, Vol.33, No.20, 2012, pp. 6600-6622.

[9] Jensen R R, "Measurement and comparison of Leaf Area Index estimators derived from satellite remote sensing techniques", International Journal of Remote Sensing, Vol.25, No.20, 2004, pp. 4251-4265.

[10] Aurélie Davranche, "Wetland monitoring using classification trees and SPOT-5 seasonal time series", Remote Sensing of Environment, Vol.114, 2010, pp. 552-562.

[11] Nikolaos G. Silleos, "Vegetation Indices: Advances Made in Biomass Estimation and Vegetation Monitoring in the Last 30 Years", Geocarto International, Vol.21, No.4, 2006, pp. 21-28.

[12] Eklundh L, "Investigating the use of Landsat thematic mapper data for estimation of forest leaf area index in southern Sweden", Canadian Journal of Remote Sensing, Vol.29, No.3, 2003, pp. 349-362.

[13] Xu L L, "Analysis on the changing characteristics and influencing factors of Panjin wetland during the past 20 years", Journal of Natural Resources, Vol.24, No.3, 2009, pp. 483-484. 